Tropical Journal of Pharmaceutical Research February 2013; 12 (1): 19-25

ISSN: 1596-5996 (print); 1596-9827 (electronic)

(c) Pharmacotherapy Group, Faculty of Pharmacy, University of Benin, Benin City, 300001 Nigeria.

All rights reserved.

Available online at http://www.tjpr.org

Original Research Article

http://dx.doi.org/10.4314/tjpr.v12i1.4

\title{
Formulation and Evaluation of Glutaraldehyde-Crosslinked Chitosan Microparticles for the Delivery of Ibuprofen
}

\author{
KC Ofokansi ${ }^{1^{*}}, \mathrm{FC}$ Kenechukwu ${ }^{1}, \mathrm{AB}$ Isah $^{2}$ and EL Okigbo ${ }^{1}$ \\ ${ }^{1}$ Drug Delivery Research Unit, Department of Pharmaceutics, Faculty of Pharmaceutical Sciences, University of Nigeria, \\ Nsukka 410001, '2Department of Pharmaceutics and Pharmaceutical Microbiology, Faculty of Pharmaceutical Sciences, \\ Ahmadu Bello University, Zaria, Nigeria.
}

*For correspondence: E-mail: kcofokansi@yahoo.com; Tel: +234-81-31245821

\section{Abstract}

\begin{abstract}
Tropical Journal of Pharmaceutical Research is indexed by Science Citation Index (Purpose: Toformulate glutaraldehyde-cross-linked chitosan-based microparticles and evaluate its suitability for the delivery of ibuprofen, a BCS class II drug.

Methods: Ibuprofen-loaded chitosan microparticles were prepared by emulsification-cross-linking technique using glutaraldehyde saturated toluene (GST) as the cross-linking agent. The microparticles were characterized with respect to morphology, particle size, microparticle yield and entrapment efficiency. The swelling behaviour of the particles and ibuprofen release were assessed in both simulated gastric fluid (SGF) without pepsin ( $\mathrm{pH}$ 1.2) and simulated intestinal fluid (SIF) without pancreatin ( $\mathrm{pH} 7.4$ ).

Results: Discrete and free-flowing microparticles of size range $100.05 \pm 8.82$ to $326.70 \pm 10.43 \mu \mathrm{m}$ were obtained. The microparticles had a high yield (69.2 to $99.2 \%)$ and exhibited greater water sorption capacity in SIF (122.2\%) than in SGF (60\%). Furthermore, the microparticles cross-linked with $10 \mathrm{ml}$ of GST entrapped the highest amount of drug (23.32 $\pm 0.97 \%)$ while those cross-linked with $25 \mathrm{ml}$ GST had the highest yield of the microparticles (99.19\%), and highest water sorption in SIF (122.2\%). Up to $93.6 \%$ of the entrapped drug was released in SIF from microparticles cross-linked with $25 \mathrm{ml}$ of GST. Drug release from microparticles cross-linked with 20 and $30 \mathrm{ml}$ each of GST showed a biphasic pattern.

Conclusions: Entrapment of ibuprofen in glutaraldehyde-cross-linked chitosan microparticles can be exploited to target and control the release of the drug and possibly reduce its gastro-erosive side effects.
\end{abstract}

Keywords: Chitosan microparticles, Ibuprofen, Oral delivery, Gastrointestinal, Glutaraldehyde.

SciSearch), Scopus, International Pharmaceutical Abstract, Chemical Abstracts, Embase, Index Copernicus, EBSCO, African Index Medicus, JournalSeek, Journal Citation Reports/Science Edition, Directory of Open Access Journals (DOAJ), African Journal Online, Bioline International, Open-J-Gate and Pharmacy Abstracts

\section{INTRODUCTION}

The efficacy of a drug can be markedly influenced by the method by which the drug is delivered. There is growing interest and investment in the use of polymer-based systems in drug discovery and product development to effectively overcome problems related to stability and bioavailability $[1,2]$. Microparticulate carrier systems made from naturally occurring biodegradable and bioadhesive (mucoadhesive) polymers have attracted considerable attention over the years [3].

Chitosan (obtained by deacetylation of chitin) is a naturally occurring cationic polymer which finds a wide array of applications due to its low production costs, biodegradability, biocompa- 
tibility, nontoxic nature and mucoadhesion [4]. Microspheres prepared with chitosan by various methods have been used for the controlled release of many drugs, among other applications $[4,5]$. Factors affecting the release of drug from chitosan microspheres include the molecular weight and concentration of chitosan, the crosslinking agent used and its concentration, process variables like stirring speed, type of oil, additives, cross-linking process used, drug-chitosan ratio etc.

Application of non-steroidal anti-inflammatory drugs (NSAIDs) in therapy is fraught with a myriad of draw-backs especially gastrointestinal side effects. Ibuprofen is a NSAID that is often used orally to relieve inflammation, fever and pain. A number of reports have focused on controlling the release of ibuprofen, with some level of success, by entrapping it in microcapsules based on mucoadhesive polymers including sodium alginate, methylcellulose, ethylcellulose, hydroxypropylmethylcellulose and sodiumcarboxymethylcellulose, either in combination or singly [6,7]. Glutaraldehyde cross-linked chitosan has been used by earlier investigators to achieve a controlled release of diclofenac sodium and as a long acting biodegradable delivery vehicle for mitoxantrone [8-10]. In those earlier reports, it was shown that drug diffusion from a chitosan matrix could be effectively controlled by cross-linking the matrix using a dialdehyde such as glutaraldehyde. It is in this vein that we set out in the present study to entrap ibuprofen in glutaraldehyde cross-linked chitosan microparticles with a view to controlling its release.

Consequently, the aim of the present investigation was to explore the potential applications of microparticles based on mediummolecular-weight chitosan cross-linked with glutaraldehyde for the controlled delivery of ibuprofen with a long-term objective of achieving a reduction in the gastro-erosive side effects of the drug.

\section{EXPERIMENTAL}

\section{Materials}

Ibuprofen (BASF, Germany), chitosan low viscous (Sigma-Aldrich, USA), acetone, concentrated hydrochloric acid, glutaraldehyde, sodium chloride (BDH, England), sodium hydroxide, Span 80 and toluene (Merck, Germany); monobasic potassium phosphate (Sigma Chemical Co., USA), petroleum ether (Fluka, Germany), liquid paraffin (May and Baker, England) were used as procured from the manufacturers without further purification. All other reagents were analytical grade and used as such. Distilled water was obtained from an allglass distillation apparatus.

\section{Preparation of glutaraldehyde saturated toluene (GST)}

Glutaraldehyde $(100 \mathrm{ml})$ and toluene $(100 \mathrm{ml})$ were placed in a beaker and stirred at $1000 \mathrm{rpm}$ for $1 \mathrm{~h}$ using a magnetic stirrer (Remi Instruments, Mumbai, India). Then, the solvent mixture was kept overnight for stabilization after which the upper toluene layer saturated with glutaraldehyde was decanted and used as glutaraldehyde saturated toluene (GST).

\section{Preparation of chitosan microparticles}

The microparticles were prepared by simple emulsification phase separation technique. Chitosan was used as a polymer and was crosslinked using glutaraldehyde saturated toluene (GST) as per the method described by Thanoo et al [9]. All the batches were formulated to contain ibuprofen and chitosan in the ratio of $1: 2$ while the volume of GST in each batch of the formulation was varied. Briefly, chitosan $(2.0 \mathrm{~g})$ was dissolved in $100 \mathrm{ml}$ of $5 \% \mathrm{v} / \mathrm{v}$ aqueous acetic acid solution. One gram of ibuprofen was dispersed in the polymer solution. The resultant mixture was extruded through a syringe $(10 \mathrm{ml}$ capacity) without a needle in $125 \mathrm{ml}$ of liquid paraffin (heavy and light, $1: 1$ ratio) containing 0.5 $\%$ v/v Span 80, and stirring was performed using a propeller stirrer (Remi Instruments, Mumbai, India) at $1000 \mathrm{rpm}$. After 15, 30, 45 and $60 \mathrm{~min}$, GST (2.5 $\mathrm{ml}$ each) was added and further stirring was continued for $2 \mathrm{~h}$. The amount of the crosslinking agent was varied from 10 to $30 \mathrm{ml}$ whereas the cross-linking time, stirring speed and the polymer-to-drug ratio were kept constant. Five batches of the microparticles denoted as $\mathrm{GST}_{10}, \mathrm{GST}_{15}, \mathrm{GST}_{20}, \mathrm{GST}_{25}$ and $\mathrm{GST}_{30}$ were formulated. Microparticles thus obtained were filtered and washed several times with petroleum ether (boiling point $20-40^{\circ} \mathrm{C}$ ) to remove any traces of oil. They were finally washed with acetone to remove excess of GST. The microparticles were then dried at the ambient temperature of $28 \pm 2{ }^{\circ} \mathrm{C}$ for $24 \mathrm{~h}$.

\section{Determination of percentage yield of microparticles}

The dried microparticles were weighed to obtain the yield of microparticles formulated per batch. The percentage (\%) yield was calculated using the formula: 
Yield $=\frac{W_{1}}{W_{2}+W_{3}} \times 100$

where $\mathrm{W}_{1}=$ weight of the microparticles, $\mathrm{W}_{2}=$ weight of the drug added, and $\mathrm{W}_{3}=$ weight of the polymer and Span 80.

\section{Particle size analysis and morphological characteristics}

The particle size of the microparticles was determined by computerized image analysis on a photomicroscope (Lieca, Germany). A quantity $(0.1 \mathrm{~g})$ from each of the batches was dispersed in a mixture of liquid paraffin and Span 80 and mounted on a slide and observed under a light microscope. With the aid of software in the microscope, the projected diameters of the particles corresponding to the particle sizes of the microparticles were determined and the mean calculated. The particle morphologies were also observed and captured by the photomicroscope.

\section{Swelling studies}

The degree of swelling of the microparticles was investigated separately in simulated gastric fluid (pH 1.2) without pepsin and simulated intestinal fluid $(\mathrm{pH}$ 7.4) without pancreatin. A dialysis membrane $9 \mathrm{~cm}$ long was activated by immersion in $50 \mathrm{ml}$ of distilled water regulated at $90 \stackrel{\circ}{C}$ for $1 \mathrm{~h}$ and thereafter washed with distilled water. A known weight of the microparticles was placed in the activated dialysis membrane which was tied at both ends and immersed in a beaker placed on a thermostated bath maintained at 37 \pm 1 oC. At 5 min intervals, the membrane was removed from each medium, dried with filter paper and weighed. The degree of swelling was calculated using the formula:

$$
H(\%)=\frac{\left(M_{2}-\mathrm{M}_{1}\right)}{M_{1}} \times 100 \cdots
$$

where $M_{1}=$ initial weight of microparticles $(g)$, and $\mathrm{M}_{2}=$ final weight of microparticles.

\section{Determination of entrapment efficiency of the microparticles}

A quantity $(100 \mathrm{mg})$ of the microparticles was placed in a beaker containing $100 \mathrm{ml}$ of phosphate buffer $(\mathrm{pH}$ 7.4). The dispersion was vortexed repeatedly to break up the microparticles and cause them to discharge their contents completely. The solution was then filtered and analyzed spectrophotometrically at a wavelength of $272 \mathrm{~nm}$ using a Uv-Vis spectrophotometer (Jenway 6405). The drug concentration in each batch of the microparticles was calculated from a Beers' plot previously determined for ibuprofen. An average of four determinations was taken as the mean drug content for each batch of microparticles. The drug entrapment efficiency (E) was calculated using the following formula:

$E(\%)=(A D L / T D L) 100$

where $A D L$ is actual drug loading and TDL is theoretical drug loading

\section{In vitro drug release studies}

The USP XXVII paddle method was adopted in this study [11]. The dissolution experiment was performed in $500 \mathrm{ml}$ of freshly prepared SIF $(\mathrm{pH}$ 7.4) and SGF (pH 1.2) maintained at $37 \pm 1 \stackrel{\circ}{\circ} \mathrm{C}$. A known quantity $(300 \mathrm{mg})$ from each batch of the microparticles was placed in the appropriate chamber of the release apparatus and agitated at $50 \mathrm{rpm}$. At predetermined time intervals, $5 \mathrm{ml}$ aliquots of the release medium were withdrawn, appropriately diluted and assayed spectrophotometrically at $272 \mathrm{~nm}$. At every interval, $5 \mathrm{ml}$ of fresh release medium was added to maintain a constant volume in the dissolution medium. The concentrations of the withdrawn samples were calculated with reference to the standard Beers' plot. Three replicate release studies were performed in each case and the mean values were taken.

\section{Statistical data analysis}

Statistical data analyses were performed using SPSS (version 16). For batch comparisons, the student's t-test was used to determine statistically significant differences at $p<0.05$.

\section{RESULTS}

The particle size distribution of the microparticles is presented in Table 1. The mean particle size $(n=50)$ of the microparticles ranged from 100.05 $\pm 8.82 \mu \mathrm{m}$ to $326.70 \pm 10.43 \mu \mathrm{m}$. Microparticles formulated with $10 \mathrm{ml}$ of glutaraldehyde saturated toluene (batch GST $_{10}$ ) had the smallest particle size while microparticles cross-linked with $25 \mathrm{ml}$ of GST possessed the largest mean particle size. The photomicrographs (pictures not shown) showed that the microparticles had a brownish and spherical appearance except for some batches that appeared to have some degree of hydration and irregular shapes, especially those cross-linked with $25 \mathrm{ml}$ and 30 ml GST. 
Table 1: Formulation and physical properties of ibuprofen-loaded chitosan microparticles

\begin{tabular}{|c|c|c|c|c|}
\hline Batch code & $\begin{array}{l}\text { Volume of cross- } \\
\text { linking agent }(\mathrm{ml})\end{array}$ & Yield (\%) & $\begin{array}{l}\text { Loading } \\
\text { efficiency }\end{array}$ & Size $(\mu \mathrm{m})^{\mathrm{a}, \mathrm{c}}$ \\
\hline $\mathrm{GST}_{10}$ & 10 & 98.53 & $23.32 \pm 0.97$ & $100.05 \pm 8.82$ \\
\hline $\mathrm{GST}_{15}$ & 15 & 69.27 & $20.67 \pm 3.11$ & $326.70 \pm 10.43$ \\
\hline $\mathrm{GST}_{20}$ & 20 & 84.43 & $19.78 \pm 1.06$ & $116.72 \pm 9.16$ \\
\hline $\mathrm{GST}_{25}$ & 25 & 99.19 & $13.88 \pm 2.83$ & $262.50 \pm 5.46$ \\
\hline $\mathrm{GST}_{30}$ & 30 & 94.23 & $12.90 \pm 1.89$ & $163.34 \pm 7.12$ \\
\hline
\end{tabular}

Discrete, spherical and free flowing microparticles were obtained using 10, 15, and $20 \mathrm{ml}$ of the cross-linking agent. Batches $\mathrm{GST}_{25}$ and $\mathrm{GST}_{30}$ which were cross-linked with 25 and $30 \mathrm{ml}$ of GST respectively, yielded irregular microparticles. The results presented in Table 1 show that the microparticle yield (percentage yield) was high. Particularly noteworthy is the batch that had the highest yield of $99.19 \%$. This occurred in microparticles cross-linked with $25 \mathrm{ml}$ of GST. Microparticles cross-linked with $15 \mathrm{ml}$ of GST had the lowest yield (69.27\%). The results of the water sorption studies are shown in Figs. 1 and 2. It can be seen from these figures that water sorption for all batches of the microparticles was higher in SIF than in SGF. Microparticles cross-linked with $25 \mathrm{ml}$ of GST showed the highest degree of swelling in SIF where $122.2 \%$ water sorption was recorded when compared to that prepared with $10 \mathrm{ml} \mathrm{GST}$ which showed a water sorption of $42.6 \%$. Water sorption for microparticles cross-linked with $30 \mathrm{ml}$ GST was, however, lower compared to that cross-linked with $25 \mathrm{ml}$ GST. In SGF, the highest water sorption capacity was shown by microparticles cross-linked with $25 \mathrm{ml}$ of GST and this was closely followed by microparticles cross-linked with $30 \mathrm{ml}$ of GST. Approximately equal water sorption values were obtained for microparticles cross-linked with 10 and $20 \mathrm{ml}$ of GST. Water absorption and the rate of water absorption by the microparticles followed the order: $\mathrm{GST}_{25}>\mathrm{GST}_{30}>\mathrm{GST}_{20}>\mathrm{GST}_{15}>\mathrm{GST}_{10}$ in SIF while the order in SGF is: $\mathrm{GST}_{15}>\mathrm{GST}_{30}$ $>\mathrm{GST}_{25}>\mathrm{GST}_{20}=\mathrm{GST}_{10}$. It is discernible from Table 1 that the entrapment efficiency of all batches of the microparticles was in the range of $12.90 \pm 1.89 \%$ to $23.32 \pm 0.97 \%$ with microparticles cross-linked with $10 \mathrm{ml}$ GST recording the highest drug entrapment. The general pattern was that drug entrapment decreased with increasing proportions of the cross-linking agent used in preparing the microparticles. Microparticles cross-linked with $10 \mathrm{ml}$ GST entrapped greater amounts ( $p \leq 0.05$ ) of ibuprofen in comparison with those crosslinked with $30 \mathrm{ml}$ of GST.

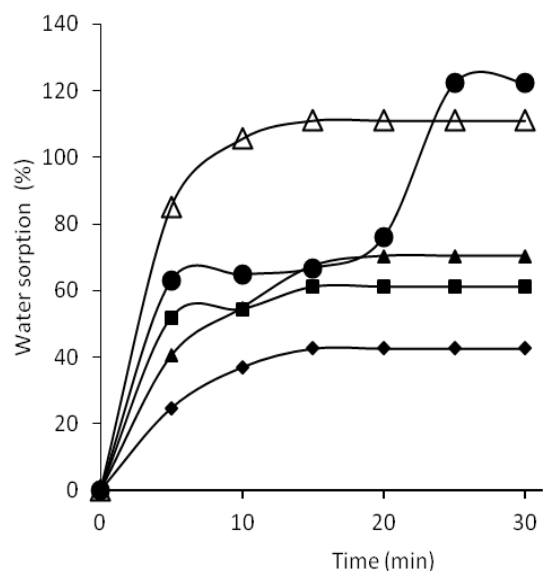

Figure 1: Swelling profiles of iboprofen microparticles in SIF. Key: GST $10(\diamond)$, GST $15(\boldsymbol{\bullet})$, GST $20(\boldsymbol{\Delta})$, GST $25(\bullet)$, GST $30(\Delta)$

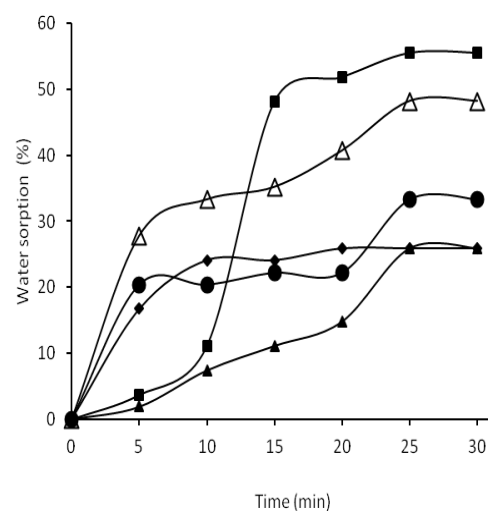

Figure 2: Swelling profiles of ibuprofen microparticles in SGF. Key: GST 10 (V), GST 15 (V), GST 20 (V), GST $25(\mathrm{~V})$, GST $30(\mathrm{~V})$.

The release profiles of ibuprofen from the microparticles in SIF and SGF are graphically represented in Figs 3 and 4 . There was a sustained release of the drug from most of the microparticles. However, drug release was higher in SIF than in SGF, and there was an initial rapid release of ibuprofen from the microparticles cross-linked with 20 and $30 \mathrm{ml}$ GST within 3 and $2 \mathrm{~h}$, respectively in SIF. A characteristic feature of the release profile of ibuprofen from the latter batches of microparticles in SIF is the biphasic pattern of release. 
Drug release in SIF was highest and more gradual and sustained from microparticles crosslinked with $25 \mathrm{ml}$ of GST where up to $93.6 \%$ of the drug was released within $10 \mathrm{~h}$. In SGF, the release of ibuprofen from the microparticles was lower and more gradual than in SIF. Drug release from the microparticles in SIF followed the order: $\mathrm{GST}_{25}>\mathrm{GST}_{20}>\mathrm{GST}_{30}>\mathrm{GST}_{10}>$ $\mathrm{GST}_{15}$ while the order in SGF is: $\mathrm{GST}_{20}>\mathrm{GST}_{30}$ $>\mathrm{GST}_{10}>\mathrm{GST}_{15}>\mathrm{GST}_{25}$.

Table 2: Higuchi release kinetic parameters of ibuprofen from ibuprofen microparticles in SIF and SGF.

\begin{tabular}{lcccc}
\hline \multirow{2}{*}{$\begin{array}{l}\text { Batch } \\
\text { code }\end{array}$} & \multicolumn{4}{c}{ Release parameter } \\
\cline { 2 - 5 } & $\mathrm{K}_{\mathrm{H}}$ & $\mathrm{r}^{2}$ & $\mathrm{~K}$ & SGF \\
\hline GST $_{10}$ & 6.893 & 0.940 & 5.734 & $r^{2}$ \\
$\mathrm{GST}_{15}$ & 5.322 & 0.817 & 3.273 & 0.994 \\
$\mathrm{GST}_{20}$ & 13.930 & 0.870 & 5.682 & 0.903 \\
$\mathrm{GST}_{25}$ & 11.930 & 0.840 & 3.190 & 0.737 \\
$\mathrm{GST}_{30}$ & 11.560 & 0.850 & 5.061 & 0.937 \\
\hline
\end{tabular}

$K_{H}=$ Higuchi release rate constant; $r^{2}=$ Correlation coefficient.

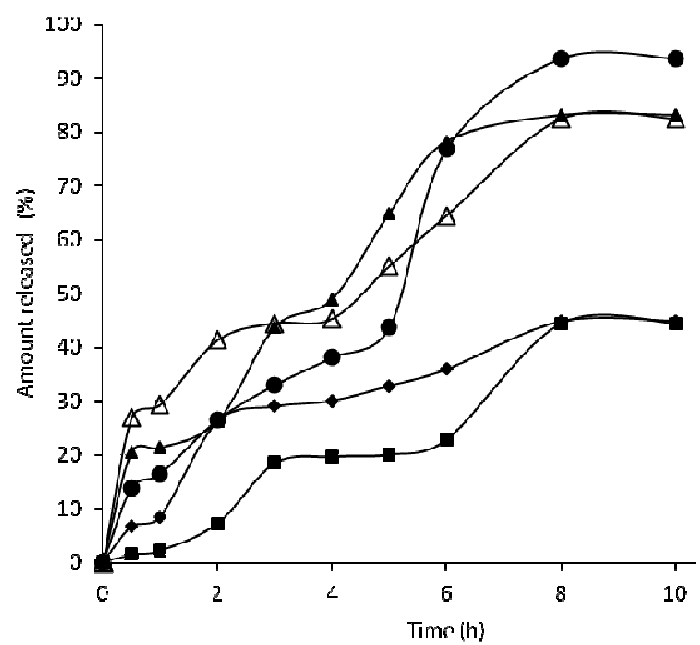

Figure 3: Release profiles of ibuprofen from the microparticles in SIF. GST $10(\diamond)$, GST 15 (घ), GST 20 $(\Delta)$, GST $25(\bullet)$, GST $30(\Delta)$.

\section{DISCUSSION}

The sizes of the microparticles were all within the micrometer range, indicating that the production process was able to achieve the intended endpoint. It would appear that the average size of the microparticles increased with an increase in the proportion of the cross-linking agent employed.

However, the microparticles cross-linked with 15 $\mathrm{ml}$ of GST had a larger size than the other batches, especially microparticles cross-linked with 20, 25 and $30 \mathrm{ml}$ GST possibly owing to incomplete cross-linking of the microparticles.

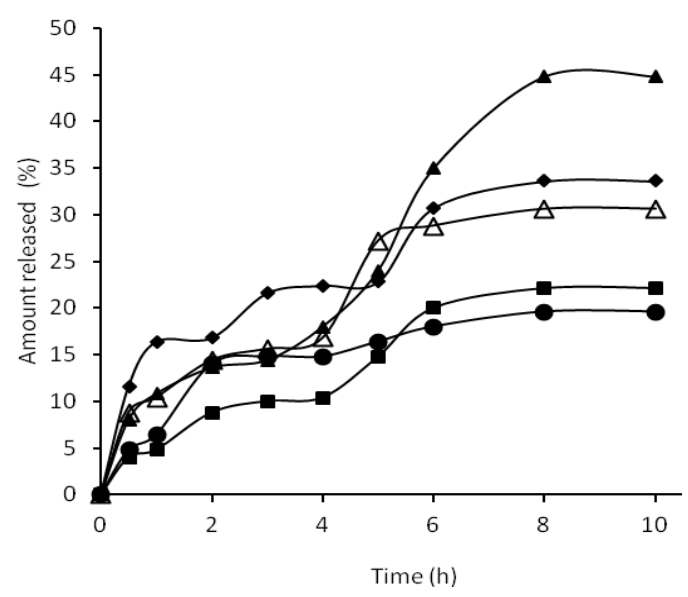

Figure 4: Release profiles of ibuprofen from the microparticles in SGF: GST $10(\bullet)$, GST 15 (घ), GST $20(\mathbf{\Delta})$, GST $25(\bullet)$, GST $30(\Delta)$

The microparticles evaluated in this study are intended for oral administration and particle size would influence the rate of drug release and subsequent pharmacokinetics [12]. The microparticle yield was high, an indication that the formulation technique adopted was reliable. There was no evidence of correlation between the proportion of cross-linking agent used in the formulation of microparticles and the microsphere yield. . Factors that influence swelling of swellabe polymers prepared by crosslinking technique include the cross-linking time and the concentration of the cross-linking agent. Cross-linked chitosan is relatively stable in acidic medium but rapidly swells and releases its encapsulated drug in an alkaline medium [13-16]. By implication, encapsulation of ibuprofen in GST cross-linked chitosan microparticles would cause a little amount of the drug to be released in the stomach thereby decreasing its corrossive effects on the gastric mucosa and would further enhance its targeting to the intestine, where the desired sustained release effects would be achieved. It is equally clear from the results of the swelling studies that microparticles crosslinked with $10 \mathrm{ml}$ of GST had the lowest water sorption capacity in the two media. This may likely be the optimum amount of the cross-linking agent needed to produce microparticles for sustained release dosage form. Conversely, batch $\mathrm{GST}_{25}$ which was cross-linked with $25 \mathrm{ml}$ of the cross-linking agent sustained the release of ibuprofen to the highest degree.

The drug entrapment efficiency is an important variable for assessing the drug loading capacity of microparticles and their drug release profiles, thus suggesting that the amount of drug that would be available at the site of absorption. This 
parameter is dependent on the process of preparation, physicochemical properties of drug, and formulation variables [17-19]. The drug entrapment efficiency was observed to be dependent on the amount of cross-linking agent used in preparing the microparticles. Microparticles cross-linked with $10 \mathrm{ml}$ of GST had higher mean drug content and thus higher loading efficiency compared to the drug content of microparticles cross-linked with $30 \mathrm{ml}$ GST (Table 1). This was the optimum amount of cross-linking agent for formulation of chitosan microparticles using a cross-linking time of $2 \mathrm{~h}$. This batch showed lower rate and degree of swelling than the other batches. Higher degree of swelling weakens secondary bonds in polymers and, thus, the lower degree of swelling in batch $\mathrm{GST}_{10}$ microparticles may have resulted in stronger attachment of the drug within the chitosan matrix. In addition, the wide variation in the drug contents of the different batches of the microparticles could be a consequence of the varying degrees of drug sedimentation and the relative partitioning of ibuprofen between the dispersed and continuous phases of the emulsion prior to cross-linking of the polymer [20].

The results depicted in Figs 4 and 5 indicate that the percentage drug released is highly dependent on the $\mathrm{pH}$ of the release media and the proportion of the cross-linking agent. The rapid release of ibuprofen from batches $\mathrm{GST}_{20}$ and $\mathrm{GST}_{30}$ in the first $30 \mathrm{~min}$ is possibly due to a burst effect caused by the leaching out of the unentrapped drug adhering to the surface of the microparticles after the initial rapid hydration and swelling. Burst release resulting in biphasic release pattern may be utilized in therapeutic design of dosage forms. This has been observed in microparticles prepared using chitosan as a polymer [4,21]. There is a lot of peripheral attachment of the drug as a result of expulsion during microsphere drying (elastic contraction as seen in gels) or drug migration as a result of solvent drag during drying. In this case, however, this may be an advantage because it would lead to a high initial blood concentration of the drug and a gradual release of the remaining drug. In arthritis and chronic pain management, the objective is always to instantly alleviate pain and inflammatory conditions. This is possible if a bolus dose of the NSAID (ibuprofen) is administered. The bolus dose, when required, would be provided by the initial burst as seen in batches $\mathrm{GST}_{20}$ and $\mathrm{GST}_{30}$. The high and rapid release of ibuprofen from the microparticles in SIF, in addition to the burst effect, may also be a result of the high rate of hydration and swelling of the microparticles in SIF, which, in turn, could be attributable to the properties of the polymer (chitosan) used in preparing the microparticles. The subsequent slow release phase could be a consequence of the decreasing residual amount of drug in the microparticles and the build-up of drug concentration in the dissolution medium in the course of time. This indicates that once the drug adhering to the microspheric surface has leached, the drug release becomes diffusioncontrolled. Moreover, chitosan possesses bioadhesive properties $[22,23]$. This is an added advantage since the transit time of the dosage form would be prolonged in the gastrointestinal tract for maximum absorption of the active ingredient. Further kinetic analysis of the release data was performed on the ibuprofen-loaded chitosan microparticles. The criterion was based on a goodness-of-fit test. The result of the different parameters derivable from the Higuchi release model [24] is presented in Table 2. The values show that batch GST $_{10}$ microparticles obeyed the Higuchi membrane diffusioncontrolled model in SIF, whereas batches GST $_{15}$ and $\mathrm{GST}_{20}$ microparticles followed the model in SGF and thus exhibited diffusion-controlled release. The implication is that cross-linking the microparticles with $10 \mathrm{ml}$ of GST increased the diffusional tendency of the incorporated drug in SIF. Similarly, cross-linking the chitosan microparticles with 15 and $20 \mathrm{ml}$ of GST diffusionally increased the release of ibuprofen in SGF.

\section{CONCLUSION}

Ibuprofen-loaded microparticles were successfully prepared using medium molecular weight chitosan by the emulsification-solvent evaporation technique using glutaraldehyde saturated toluene as the cross-linking agent. Glutaraldehyde cross-linked medium molecular weight chitosan could be useful in controlling the release of ibuprofen with a potential of reducing its gastrointestinal side effects and dosing frequency. Further studies would seek to evaluate these formulations by employing inflammation models in experimental animals.

\section{REFERENCES}

1. Alagusundaram M, Madhu SC, Umashankari K, Attuluri VB, Lavanya $C$, Ramkanth $S$. Microspheres as a novel drug delivery system- a review. Int $J$ ChemTech Res. 2009; 1(3): 526-534.

2. Coombes A, Tasker S, Lindbal M, Holmgreen K, Hoste $\checkmark$. Biodegradable polymeric microparticles for drug delivery and vaccine formulation: The surface attachment of hydrophilic species using the concept of poly(ethylene)glycol achoring segments. Biomaterials. 1997; 18: 1153-1161.

3. Patel JK, Patel RP, Amin AF, Patel MM. Formulation and evaluation of mucoadhesive glipizide 
microspheres. AAPS PharmSciTech.2005; 6(1): E49-E55.

4. Rahul N, Reddy BH, Kumar CKA, Kumar KJ. Application of chitosan microspheres as drug carriers: a review. J Pharm Sci Res. 2009; 2: 1-12.

5. Saravana KA, Ramaswamy NM. Chitosan microspheres as potential vaccine delivery systems. Int J Drug Deliv. 2010: 3: 43-50.

6. Bantu AR, Shivalingam MR, Reddy YV, Sunitha N, Tejopavan V. Preparation and evaluation of mucoadhesive microcapsules of ibuprofen for controlled release. IRJP.2011; 2: 257-260.

7. Kristmundsdottri $T$, Ingvarsdottri K. Ibuprofen microcapsules: effect of production variables on microcapsule properties. Drug Dev Ind Pharm. 1994; 20: 769-778.

8. Jameela SR, Jayakrishnan A. Glutaraldehyde crosslinked chitosan microspheres as a long acting biodegradable drug delivery vehicle: studies on the in vitro release of mitoxantrone and in vivo degradation of microspheres in rat muscle. J Control Rel. 1995; 16:769-775.

9. Thanoo BC, Sunny MC, Jayakrishnan A. Cross-linked chitosan microspheres: preparation and evaluation as a matrix for the controlled release of pharmaceuticals. J Pharm Pharmacol. 1992; 44 . 283-286.

10. Kulkarni VH, Kulkarni PV, Keshavayya J. Glutaraldehyde-crosslinked chitosan beads for controlled release of diclofenac sodium. J Appl Polym Sci. 2007; 103: 211-217.

11. The United States Pharmacopeial Convention. The United States Pharmacopeia. XXVI. Rockville, MD: The United States Pharmacopeial Convention, Inc 2003; 2528.

12. Berchane NS, Carson KH, Rice-Ficht AC, Andrews MJ. Effect of mean diameter and polydispersity of PLG microspheres on drug release: Experiment and theory. Int J Pharm. 2007 DOI: 10.1016/j.ijpharm.2006.12.037.

13. Vasir JK, Tambwekar K, Garg S. Bioadhesive microspheres as a controlled drug delivery system. Int J. Pharm. 2003; 255: 13-32.
14. Saravana KA, Ramaswamy NM. Chitosan microspheres as potential vaccine delivery systems. Int J Drug Deliv. 2010; 3: 43-50.

15. Berthold A, Cremer K, Kreuter J. Preparation and characterization of chitosan microspheres as drug carrier for prednisolone sodium phosphate as model for anti-inflammatory drugs. J Control Release. 1996; 39: 17-25.

16. Genta I, Perugini P, Pavanetto F. Different molecular weight chitosan microspheres: influence on drug loading and drug release. Drug Dev Ind Pharm. 1998; 24(8): 779-784.

17. Gohel MC, Amin AF. Formulation optimization of controlled release diclofenac sodium microspheres using factorial design. J Control Release. 1998; 51 : 115-122.

18. Pamujula S, Graves RA, Kishore V, Mandal TK. Preparation and in vitro characterization of amifostine biodegradable microcapsules. Eur $J$ Pharm Biopharm. 2004; 57: 213-218.

19. Chowdary KPR, Rao YS. Design and in vitro and in vivo evaluation of mucoadhesive microcapsules of glipizide for oral controlled release: a technical note. AAPS PharmSciTech. 2003;4:E39.

20. Ofokansi KC, Adikwu MU. Formulation and evaluation of microspheres based on gelatin-mucin admixtures for the rectal delivery of cefuroxime sodium. Trop $J$ Pharm Res. 2007; 6(4): 825-832.

21. Lehr CM, Bouwstra JA, Schacht EH, Junginger HE. In vitro evaluation of mucoadhesive properties of chitosan and some other natural polymers. Int $J$ Pharm. 1992; 78: 43-48.

22. Ida G, Monica C, Annalia A, Bice C, Luisa M. Influence of glutaraldehyde on drug release and mucoadhesive properties of chitosan microspheres. Carbohyd Polym Sci 1998; 42: 81 88.

23. Gupta KC, Ravi-Kumar MNV. Semi-interpenetrating polymer network beads of cross-linked chitosanglycine for controlled release of chlorpheniramine maleate. J Appl Polym Sci 2000; 76: 672-683.

24. Higuchi T. Mechanism of sustained action medication. Theoretical analysis of rate of solid drugs dispersed in solid matrices. J Pharm Sci. 1963; 52: 11451149. 